\title{
Occupation and mental health in a national UK survey
}

\author{
Stephen Alfred Stansfeld • F. R. Rasul • \\ J. Head · N. Singleton
}

Received: 2 March 2009/Accepted: 9 December 2009/Published online: 24 December 2009

(c) The Author(s) 2009. This article is published with open access at Springerlink.com

\begin{abstract}
Objectives To measure the prevalence of common mental disorder (CMD) by occupation in a representative sample of Great Britain and to identify occupations with increased and decreased risk of CMD.

Methods A cross-sectional interview-based survey was carried out including 5,497 working male and female respondents, 16-64 years from a stratified random survey of private households in Britain. Occupations were classified by the Standard Occupational Classification (SOC) into four groups: major, sub-major, minor and constituent unit groups. Common Mental Disorder was measured by the Revised Clinical Interview Schedule.

Results Major SOC groups with higher prevalence of common mental disorder included clerical and secretarial, sales, and personal and protective services whereas craft and related, 'other' professional occupations and plant and machine operatives had lower prevalence compared to $13 \%$ overall prevalence in all adults. In sub-major SOC groups
\end{abstract}

S. A. Stansfeld · F. R. Rasul

Centre for Psychiatry, Queen Mary University of London,

Wolfson Institute of Preventive Medicine, Barts and the London

School of Medicine and Dentistry, London EC1M 6BQ, UK

J. Head

Department of Epidemiology and Public Health,

University College London Medical School,

University College London, London WC1E 6BT, UK

N. Singleton

UK Drug Policy Commission (UKDPC),

11 Park Place, London SW1A 1LP, UK

\section{S. A. Stansfeld ( $\square)$}

Centre for Psychiatry Old Anatomy Building,

Charterhouse Square, London EC1M 6BQ, UK

e-mail: s.a.stansfeld@qmul.ac.uk managers and administrators, teaching professionals, clerical and secretarial, 'other' sales and personal service occupations had higher prevalence whereas many professional and skilled occupations had lower prevalence. Specific SOC unit groups with higher prevalence included primary and secondary teachers, welfare community, youth workers, security staff, waiters, bar staff, nurse auxiliaries and care assistants. General managers in government and large organizations $(\mathrm{OR}=2.79,95 \%$ CI $1.41-5.54)$, managers in transport and storing $(\mathrm{OR}=2.44,95 \% \mathrm{CI}$ 1.18-5.03), buyers and mobile sales persons $(\mathrm{OR}=2.48$, 95\% CI 1.09-5.60), sales occupations (NES) (OR $=2.78$, $95 \%$ CI 1.25-6.19) and clerks (NES) $(\mathrm{OR}=2.71,95 \% \mathrm{CI}$ 1.59-4.61) had increased risk of common mental disorder relative to specialist managers adjusting for social and financial factors and physical ill-health.

Conclusions Occupations with higher risk of common mental disorder may be typified by high levels of job demands, especially emotional demands and lack of job security. The reasons why occupations have low rates of common mental disorder are varied and may include high levels of job discretion, good job training and clearly defined job tasks.

Keywords Occupations - Mental health ·

Cross-sectional studies · Work load

\section{Introduction}

Over recent decades, there has been a shift in the focus of occupational health from physical hazards in the workplace to the impact of the psychosocial work environment on health [18]. The psychosocial environment at work and its effect on health continues to be an important, although 
controversial, international issue $[1,2,14,28]$. Given the changing nature of work, it is important to understand how psychosocial issues may contribute to mental ill-health. One research theme has focussed on examining work characteristics and relating them to mental ill-health. Another approach to this issue has been to try and to identify particular occupations that may be more stressful.

Many studies have documented the association between psychosocial work characteristics and adverse psychological outcomes [3, 6, 13, 14, 27, 29]. These studies have examined associations between psychosocial work characteristics and common mental disorder, usually depression, without taking account of different occupations. It is not clear from these studies whether some occupations are associated with a higher or lower prevalence of common mental disorder. This gap in knowledge arises partly because of the difficulties in studying large samples of workers across a range of occupations with the same measure of common mental disorder.

There are relatively few studies comparing rates of mental ill-health between occupations $[4,8,21,31]$. The purpose of comparing rates of common mental disorder across different occupations is to identify occupations with high or low rates of disorder that might be, respectively, either hazardous or protective of mental health and may provide clues to work-related aetiological factors for common mental disorder. Work in general is likely to be beneficial for mental health as studies of early retirees have shown for men [5].

The objectives of the proposed research were to determine the prevalence of common mental disorder by occupation amongst current workers and the risk for common mental disorder adjusting for sociodemographic factors and physical ill-health in data from the Second UK Survey of Psychiatric Morbidity amongst adults living in private households in Britain [24].

\section{Methods}

This paper is based on data from the survey of psychiatric morbidity amongst adults living in private households, carried out by the Office for National Statistics (ONS) in 2000. The main aim of the survey was to collect data on the prevalence of mental health problems amongst adults living in private households in Great Britain.

\section{Sample}

The surveyed population consisted of people aged 1674 years living in private households included in the small user Postcode Address File (PAF) in England, Wales and Scotland. A sample of addresses was drawn from the PAF using a two-stage approach. Interviewers visited the 15,804 selected addresses to identify private households with at least one person aged 16-74 years. The Kish grid method was used to select systematically one person in each household [24]. From an eligible sample of 12,792 addresses, interviews were obtained with 8,516 people, a response rate of $69.5 \%$. Informed consent was obtained for participation in the interviews. For the analyses in this paper, a sample of 5,497 men and women between 16 and 64 years who were currently working, or had been working in the last year were selected. In this sample, $94 \%$ were currently working, $2 \%$ were unemployed and $2 \%$ were economically inactive. People who scored positively for psychosis were excluded from these analyses.

\section{Instruments}

Common mental disorders in the week preceding interview were assessed in lay administered CAPI interviews using the revised version of the Clinical Interview Schedule (CIS-R) [16]. Six diagnostic categories are obtained from the CIS-R: generalised anxiety disorder, mixed anxiety and depressive disorder, depressive episode, phobias, obsessive-compulsive disorder and panic disorder. An alternative, simpler definition of disorder, used in this paper, is the presence of a CIS-R score of 12 or above. This gives a slightly lower prevalence of 'any neurotic disorder' than that obtained when individual disorders are identified separately. We did not examine psychotic disorders as the association with occupation may be different to common mental disorders [19].

\section{Covariates}

Data were collected on self-perceived health status and long-standing illness, personal characteristics: age, marital status, ethnicity, education and employment, income and debt, housing tenure and stability and quality of accommodation.

\section{Occupation and industry coding}

People who were currently in paid employment were asked about the nature of their present job. This included full or part time work, if they were an employee or self-employed, and if they had a management or supervisory role. Job title, a description of what their job entailed (including any necessary qualifications or training), what the organisation they worked for mainly did or made were recorded. For any respondent who was not currently in paid employment, but who had previously been, this information was collected about their last job. These descriptions were then coded, 
using the Standard Occupational Classification 1990 (SOC) [20].

\section{Standard Occupational Classification}

The SOC consists of four levels: the major groups, submajor groups, minor groups and constituent unit groups. At the most detailed level, there are 374 unit groups, each with a 3-digit classification. Each occupational unit group is allocated to one of 77 minor groups, one of 22 sub-major groups, and one of 9 major groups. The major group structure is a set of broad occupational categories, which are designed to bring together unit groups that are similar in terms of the qualifications, training, skills and experience [20].

\section{Analysis}

The prevalence of common mental disorder (CIS-R score $\geq 12$ ) was calculated for SOC major, sub-major, minor, and unit groups. Occupational groups with high and low-prevalence were defined as $2 \%$ greater or less than the overall prevalence based upon the standard error of $1 \%$ for the overall prevalence of common mental disorder for major SOC groups. Crude odds ratios and odds ratios adjusted for age, sex, marital status, family type, housing tenure, financial difficulties and long-standing physical illness were estimated using logistic regression. All analyses were weighted to take account of the complex sampling design.

\section{Results}

\section{Numbers in SOC Groups}

Managers and administrators and clerical and secretarial occupations were the two largest major SOC groups (16\%), with $7-11 \%$ in each of the other major SOC groups. Amongst sub-major groups, clerical occupations (16\%), personal service occupations (15\%), and other sales occupations $(11 \%)$ were the largest groups for women. Managers and administrators $(15 \%)$ were the largest group for men. Each minor SOC groups constituted $6 \%$ or less of the sample.

Prevalence of common mental disorder by major SOC group

The prevalence of common mental disorder (CIS-R score $\geq 12$ ) by major SOC groups ranged between 9 and 17\%. Table 1 illustrates the major SOC groups with high and low-prevalence of common mental disorder in men and
Table 1 Prevalence of common mental disorder by major SOC group

\begin{tabular}{llll}
\hline & All & Men & Women \\
\hline $\begin{array}{l}\text { Overall prevalence } \\
\text { High prevalence groups }\end{array}$ & $13(12-15)$ & $11(9-12)$ & $17(15-19)$ \\
$\quad$ Clerical and Secretarial & $16(13-19)$ & & \\
Managers and Administrators & & $13(11-16)$ & \\
$\begin{array}{l}\text { Personal and protective } \\
\text { service }\end{array}$ & $15(12-19)$ & & \\
Sales & $17(17-21)$ & & $20(15-25)$ \\
Low prevalence groups & & & \\
Craft and Related & $11(8-14)$ & & $15(11-19)$ \\
occupations & & & $15(10-19)$ \\
Managers and Administrators & & & \\
'Other' occupations & $11(8-14)$ & $8(4-12)$ & $(6-20)$ \\
Plant and machine operatives & $9(6-12)$ & $8(5-11)$ & $13(11-20)$ \\
Professional occupations & $11(8-14)$ & $8(5-11)$ & $15(5)$ \\
\hline
\end{tabular}

All values are percentage $(95 \% \mathrm{CI})$

women. Major SOC groups with a higher prevalence included clerical and secretarial, sales, and personal and protective service occupations compared to the $13 \%$ overall prevalence in all adults. Craft and related, 'other', professional occupations and plant and machine operatives had a lower prevalence of common mental disorder.

Women had a higher prevalence of common mental disorder than men across all major SOC groups. For example, women in professional occupations had almost twice the prevalence of common mental disorder in men in professional occupations (15 vs. $8 \%$ ). Women in sales had a higher prevalence compared to the overall prevalence in women but women in 'other' occupations, professional occupations, managerial and administrative posts, and female plant and machine operatives had a lower prevalence of common mental disorder. For men, there was a higher prevalence in managerial and administrative occupations but lower prevalence in professional occupations, plant and machine operatives and 'other' occupations (prevalence of $8 \%$ ), compared to an $11 \%$ overall prevalence (Table 1).

Prevalence of common mental disorder by sub-major SOC group

Table 2 shows sub-major SOC groups with high and lowprevalence of common mental disorder in all adults, and men and women separately. Compared to the $13 \%$ overall prevalence of common mental disorder in all adults submajor SOC groups with higher prevalence included managers and administrators, teaching professionals, other associate professional, clerical and secretarial, 'other' sales and personal service occupations. Sub-major SOC groups 
Table 2 Prevalence of common mental disorder by sub-major SOC group

\begin{tabular}{|c|c|c|c|}
\hline & All & Men & Women \\
\hline Overall prevalence & $13(12-15)$ & $11(9-12)$ & $17(15-19)$ \\
\hline \multicolumn{4}{|l|}{ High prevalence groups } \\
\hline Buyers, brokers and sales reps & & & $30(13-48)$ \\
\hline Clerical occupations & $16(13-19)$ & & $20(16-24)$ \\
\hline Managers and Administrators & $15(12-17)$ & $14(10-17)$ & \\
\hline Other associate professional occupation & $18(14-22)$ & $13(7-19)$ & $24(16-31)$ \\
\hline Other sales occupations & $18(14-22)$ & $16(7-25)$ & $19(14-24)$ \\
\hline Personal service occupations & $16(13-20)$ & $13(6-20)$ & \\
\hline Secretarial occupations & $15(10-20)$ & & \\
\hline Skilled construction trades & & $13(6-19)$ & \\
\hline Teaching professionals & $15(11-20)$ & $13(6-19)$ & \\
\hline \multicolumn{4}{|l|}{ Low prevalence groups } \\
\hline Buyers, brokers and sales representatives & & $6(0-12)$ & \\
\hline Clerical occupations & & $9(5-14)$ & \\
\hline Drivers and mobile machine operators & $9(4-14)$ & $7(2-11)$ & \\
\hline Health associate professionals & $11(6-16)$ & & $11(6-16)$ \\
\hline Industrial plant and machine operators, assemblers & $9(6-12)$ & $9(5-12)$ & $9(3-15)$ \\
\hline Managers and proprietors in agriculture services & & & $12(6-17)$ \\
\hline Other elementary occupations & & $8(4-13)$ & $15(10-20)$ \\
\hline Other professional occupations & $10(5-15)$ & $8(2-14)$ & \\
\hline Other skilled trades & $10(7-14)$ & & \\
\hline Protective service occupations & $11(4-18)$ & & \\
\hline Science and engineering associate professionals & $11(6-16)$ & $6(1-11)$ & \\
\hline Science and Engineering professionals & $8(3-13)$ & & \\
\hline Secretarial occupations & & & $14(9-19)$ \\
\hline Skilled engineering trades & $10(5-15)$ & & \\
\hline
\end{tabular}

All values are percentage (95\% CI) teaching professionals, other associate professionals, skilled construction trades, personal service and other sales occupations. Those with a lower prevalence included science and engineering professionals, other professional occupations, clerical occupations, buyers, brokers and sales representatives, industrial plant and machine operators, assemblers, drivers and mobile machine operators, other elementary occupations.

Prevalence of common mental disorder by minor SOC group

Table 3 shows minor SOC groups and specific additional SOC unit groups with high and low prevalence of common mental disorder. Specific additional SOC unit groups were selected for examination based on earlier research that suggested that these groups might be especially vulnerable. The prevalence amongst some minor SOC groups needs to be interpreted with caution, as there were few respondents in some categories. Nevertheless, compared to the $13 \%$ overall common mental disorder prevalence in minor SOC groups, those groups with a higher prevalence included general managers in government and large organisations, 
Table 3 High and low prevalence of common mental disorder by minor SOC groups and specific additional SOC groups

\begin{tabular}{|c|c|}
\hline & $\begin{array}{l}\text { Percentage } \\
(95 \% \text { CI })\end{array}$ \\
\hline \multicolumn{2}{|l|}{ Minor SOC Groups } \\
\hline Overall prevalence & $13(12-15)$ \\
\hline \multicolumn{2}{|l|}{ High prevalence groups } \\
\hline Administration staff in government & $15(6-23)$ \\
\hline Artistic, sports etc. professionals & $18(9-26)$ \\
\hline Catering & $20(13-27)$ \\
\hline Clerks NES & $27(19-35)$ \\
\hline Clerical and secretarial occupations NES & $16(4-29)$ \\
\hline Filing record clerks & $20(10-30)$ \\
\hline General managers in government and large organisations & $26(15-38)$ \\
\hline Health and related occupations & $19(13-25)$ \\
\hline Managers and administrators & $16(7-26)$ \\
\hline Managers in transport and storing & $24(11-37)$ \\
\hline Other craft related trades NES & $16(3-28)$ \\
\hline Professional technical occupations NES & $24(12-36)$ \\
\hline Sales occupations NES & $26(8-45)$ \\
\hline Sales check out assistants & $16(12-20)$ \\
\hline Scientific technicians & $18(7-30)$ \\
\hline Secretarial etc. personnel & $16(9-22)$ \\
\hline Teaching professionals & $15(11-20)$ \\
\hline Vehicle trades & $15(4-25)$ \\
\hline Welfare associate professionals & $21(10-31)$ \\
\hline \multicolumn{2}{|l|}{ Low prevalence groups } \\
\hline Business and finance associate professionals & $9(3-14)$ \\
\hline Business and finance professionals & $6(0-11)$ \\
\hline Computer analysts, programmers & $9(2-15)$ \\
\hline Engineers and technologists & $8(2-15)$ \\
\hline Electrical and electronic trades & $7(1-13)$ \\
\hline Metal forming, welding etc. trades & $7(0-14)$ \\
\hline Natural scientists & $6(0-14)$ \\
\hline Professional occupations NES & $9(1-17)$ \\
\hline Stores despatch clerks and keepers & $7(2-12)$ \\
\hline Textile garment trades & $9(0-18)$ \\
\hline Woodworking trades & $9(2-17)$ \\
\hline \multicolumn{2}{|l|}{ Specific additional SOC Groups } \\
\hline \multicolumn{2}{|l|}{ High prevalence groups } \\
\hline Bar staff & $29(13-46)$ \\
\hline Care assistants & $19(12-27)$ \\
\hline Chefs & $16(6-25)$ \\
\hline Cleaners and domestics & $15(9-21)$ \\
\hline Nurse auxiliaries & $19(6-33)$ \\
\hline Secondary teachers & $18(10-26)$ \\
\hline Security staff & $18(4-32)$ \\
\hline Teachers in primary education & $19(9-30)$ \\
\hline Welfare community, youth workers & $21(8-35)$ \\
\hline Waiters & $18(5-32)$ \\
\hline \multicolumn{2}{|l|}{ Low prevalence groups } \\
\hline Drivers of road goods vehicles & $9(3-15)$ \\
\hline Police officers etc. & $4(0-8)$ \\
\hline
\end{tabular}

managers in transport and storing, welfare associate professionals, respondents in professional technical occupations not elsewhere stated (NES), catering and sales occupations NES, filing record clerks and clerks NES.

The prevalence of common mental disorder was lower in natural scientists, engineers and technologists, business and financial professionals, business and finance associate professionals, professional occupations NES, stores despatch clerks and keepers, electrical and electronic trades, metal forming, welding, etc. trades, woodworking trades, computer analysts, programmers, and textile garment trades compared to the overall prevalence in minor SOC groups.

Compared to the $13 \%$ overall prevalence in specific additional SOC groups, specific additional SOC groups with a higher prevalence of common mental disorder included teachers in primary and secondary (but not higher education), welfare community, youth workers, security staff, waiters, bar staff, nurse auxiliaries and care assistants. Other specific unit groups with a slightly higher prevalence of common mental disorder compared to the overall prevalence included chefs, cleaners and domestics. The prevalence of common mental disorder was much lower in police officers, etc. and in drivers of road goods vehicles.

Risk of common mental disorder by major SOC group

Table 4 shows major SOC groups significantly associated with risk of common mental disorder. In unadjusted analysis of all respondents plant and machine operatives had a reduced risk of common mental disorder (OR $0.60 \mathrm{CI}$ 0.43-0.85) compared to managers and administrators which remained after full adjustment for social, financial and ill health (OR 0.55 CI 0.38-0.78). Similarly, in unadjusted analysis in men there was a reduced risk of common mental disorder in professional (OR 0.58 CI 0.37-0.91), 'other' occupations (OR $0.56 \mathrm{CI} 0.32-0.97$ ) and plant and machine operatives (OR 0.56 CI $0.37-0.85$ ) which remained significant after full adjustment (professional occupations OR 0.63 CI 0.44-0.99), ('other' occupations OR 0.55 CI 0.31-0.97) (plant and machine operatives OR 0.47 CI $0.30-0.73$ ). There was no association between major SOC group and reduced risk of common mental disorder in women.

Risk of common mental disorder

by sub-major SOC group

In unadjusted analysis of all respondents and compared to managers and administrators sub-major SOC groups associated with a significantly reduced risk of common mental disorder included science and engineering professionals 
(OR 0.50 CI 0.27-0.92), industrial plant and machine operators, assemblers (OR 0.55 CI 0.36-0.85), drivers and mobile machine operators (OR 0.59 CI $0.35-0.97$ ) (Table 4). This reduced risk remained significant in science and engineering professionals (OR 0.54 CI 0.29-1.00), industrial plant and machine operators, assemblers (OR 0.43 CI 0.28-0.68), drivers and mobile machine operators (OR 0.57 CI 0.34-0.97) after additional adjustment for sociodemographic, financial factors and ill-health. In addition, a significantly reduced risk of common mental disorder became apparent in health associate professionals (OR 0.50 CI 0.29-0.88), and 'other' elementary occupations (OR 0.58 CI 0.39-0.85) after adjustment. In separate unadjusted analyses by sex, there was a significantly reduced risk of common mental disorder in men in other professional occupations (OR 0.40 CI 0.17-0.94), drivers and mobile machine operators (OR $0.48 \mathrm{CI} 0.26-0.87$ ) and industrial plant and machine operators and assemblers (OR 0.48 CI 0.26-0.87). In further analysis, after adjustment for sociodemographic, financial factors and ill health the reduced risk still remained significant in drivers and mobile machine operators (OR 0.42 CI 0.22-0.78), was no longer significant in other professional occupations (OR $0.47 \mathrm{CI}$
0.20-1.11), but became significant in clerical occupations (OR 0.52 CI 0.30-0.90), and industrial plant and machine operators, assemblers (OR 0.48 CI 0.27-0.83). A reduced risk of common mental disorder only became apparent in female industrial plant and machine operators, assemblers (OR 0.48 CI 0.22-1.05) after adjustment for sociodemographic, financial factors and ill health (OR 0.32 CI 0.14 $0.73)$

Risk of common mental disorder by minor SOC group and specific additional SOC unit groupings

In unadjusted analysis compared to specialist managers minor SOC groups with an increased risk of common mental disorder included general managers in government and large organisations (OR 2.79 CI 1.41-5.54), managers in transport and storing (OR 2.44 CI 1.18-5.03), professional technical occupations NES (OR 2.43 CI 1.204.91), filing record clerks (OR 1.96 CI 1.00-3.84), clerks NES (OR 2.71 CI 1.59-4.61), catering occupations (OR $1.97 \mathrm{CI} 1.14-3.40$ ), health and related occupations (OR 1.86 CI 1.08-3.19), buyers/mobile salespersons (OR 2.48 CI 1.09-5.60) and sales occupations NES (OR 2.78

Table 4 Odds of common mental disorder by major, sub-major and minor SOC group

\begin{tabular}{|c|c|c|c|c|}
\hline & $\mathrm{All}^{\mathrm{a}}$ & $\mathrm{All}^{\mathrm{b}}$ & $\operatorname{Men}^{\mathrm{a}}$ & $\operatorname{Men}^{\mathrm{b}}$ \\
\hline \multicolumn{5}{|l|}{ Major } \\
\hline Managers and administrators & 1.00 & 1.00 & 1.00 & 1.00 \\
\hline 'Other' occupations & $0.78(0.55-1.10)$ & $0.61(0.42-0.87)$ & $0.56(0.32-0.97)$ & $0.55(0.31-0.97)$ \\
\hline Plant and machine operatives & $0.60(0.43-0.85)$ & $0.55(0.38-0.78)$ & $0.56(0.37-0.85)$ & $0.47(0.30-0.73)$ \\
\hline Professional occupations & & & $0.58(0.37-0.91)$ & $0.63(0.44-0.99)$ \\
\hline \multicolumn{5}{|l|}{ Sub-major } \\
\hline Managers and administrators & 1.00 & 1.00 & 1.00 & 1.00 \\
\hline Clerical occupations & & & $0.60(0.36-1.01)$ & $0.52(0.30-0.90)$ \\
\hline Drivers and mobile machine operators & $0.59(0.35-0.97)$ & $0.57(0.34-0.97)$ & $0.48(0.26-0.87)$ & $0.42(0.22-0.78)$ \\
\hline Health associate professionals & $0.70(0.41-1.20)$ & $0.50(0.29-0.88)$ & & \\
\hline Industrial plant and machine operators, assemblers & $0.55(0.36-0.85)$ & $0.43(0.28-0.68)$ & $0.60(0.36-1.02)$ & $0.48(0.27-0.83)$ \\
\hline Other elementary occupations & $0.79(0.55-1.14)$ & $0.58(0.39-0.85)$ & & \\
\hline Other professional occupations & & & $0.40(0.17-0.94)$ & $0.47(0.20-1.11)$ \\
\hline Science and Engineering Professionals & $0.50(0.27-0.92)$ & $0.54(0.29-1.00)$ & & \\
\hline \multicolumn{5}{|l|}{ Minor } \\
\hline Specialist managers & 1.00 & 1.00 & & \\
\hline Buyers and Mobile Salespersons & $2.48(1.09-5.60)$ & $2.56(1.08-6.07)$ & & \\
\hline Clerks NES & $2.71(1.59-4.61)$ & $1.83(1.04-3.22)$ & & \\
\hline Filing record clerks & $1.96(1.00-3.84)$ & $1.49(0.74-3.00)$ & & \\
\hline General managers in government and large organisations & $2.79(1.41-5.54)$ & $3.07(1.51-6.24)$ & & \\
\hline Managers in transport and storing & $2.44(1.18-5.03)$ & $2.91(1.37-6.19)$ & & \\
\hline Sales occupations NES & $2.78(1.25-6.19)$ & $1.58(0.67-3.70)$ & & \\
\hline
\end{tabular}

All values are OR $(95 \% \mathrm{CI})$

${ }^{\text {a }}$ Unadjusted for social, financial and ill- health factors

b Adjusted for social, financial and ill- health factors 
Table 5 Prevalence of common mental disorder in SOC groups in construction and human health activities

\begin{tabular}{llll}
\hline Construction & $\begin{array}{l}\text { Percentage } \\
(95 \% \mathrm{CI})\end{array}$ & $\begin{array}{l}\text { Human health } \\
\text { activities }\end{array}$ & $\begin{array}{l}\text { Percentage } \\
(95 \% \text { CI })\end{array}$ \\
\hline $\begin{array}{l}\text { Overall } \\
\text { High prevalence groups } \\
\text { Clerical and secretarial occupations }\end{array}$ & $13(12-15)$ & Overall \\
$\begin{array}{l}\text { Low prevalence groups } \\
\text { Craft related occupations } \\
\text { Managers and administrators }\end{array}$ & $9(11-43)$ & Personal and protective service occupations \\
& $4(0-9)$ & $\begin{array}{l}\text { Clerical and secretarial occupations } \\
\text { Professional occupations }\end{array}$ \\
\hline
\end{tabular}

CI 1.25-6.19) (Table 4). In further analysis after taking into account socio-demographic, financial factors and ill health, there was a significantly increased risk of common mental disorder in general managers in government and large organisations (OR 3.07 CI 1.51-6.24), managers in transport and storing (OR 2.91 CI 1.37-6.19), clerks NES (OR 1.83 CI 1.04-3.22), and buyers/mobile sales persons (OR 2.56 1.08-6.07) but not in professional technical occupations NES (OR 1.85 CI 0.89-3.86), filing record clerks (OR 1.49 CI 0.74-3.00), catering occupations (OR 1.31 CI 0.74-2.33), health and related occupations (OR 1.31 CI 0.74-2.33), sales occupations NES (OR 1.58 CI 0.67-3.70). There was no significant association between any minor SOC group and a reduced risk of common mental disorder.

In unadjusted analysis, there was a significantly increased risk of common mental disorder in bar staff (OR 3.74 CI 1.46-9.58). This increased risk of common mental disorder in bar staff remained significant after adjustment for age, sex and age by sex interaction (OR 3.39 CI 1.308.82). However, bar staff were not at significantly increased risk of common mental disorder after taking sociodemographic confounders into account (OR 2.52 CI 0.95-6.72) and neither after additional adjustment for long standing physical illness (OR 2.21 CI 0.83-5.92).

Occupation by industry cross classifications

The stressfulness of occupations may depend on their sectoral context: thus, it may differ across different industries. The cross classification of occupation and industry may give an insight into whether occupational factors or specific aspects of industries relate to common mental disorder. Table 5 shows the prevalence of common mental disorder in major SOC groups within 2 Standard Industrial Classification (SIC) categories, occupations in construction and occupations in human health activities (HHA). This analysis determined whether certain occupational groups within industrial sectors were more at risk of common mental disorder. The overall prevalence of common mental disorder in major SOC groups cross classified by these 2 SIC categories was $13 \%$. Clerical and secretarial occupations in construction and personal and protective service occupations in Human Health Activities had higher prevalences of common mental disorder compared to the overall prevalence. By contrast managers and administrators, craft related occupations in construction, and clerical and secretarial occupations in HHA had lower prevalences. Clerical and secretarial occupations in construction had a much higher prevalence of common mental disorder than clerical and secretarial occupations in HHA.

Prevalence of neurotic disorders

Mixed anxiety/depressive disorder had the greatest prevalence and was more frequent in women than men across all major and sub major SOC groups. Mixed anxiety/depressive disorder was also the most frequent neurotic disorder across minor SOC groups except in textile, garment trades, security service occupations, 'other' transport machine operatives and plant and machine operatives in whom generalised anxiety disorder was more frequent.

Analysis of 1993-2000 combined data

We also carried out analyses combining current data with data from the previous national psychiatric morbidity survey from 1993 (not reported) [26]. Overall, there were few changes in prevalence rates of common mental disorder by occupation between 1993 and 2000. By combining the datasets, we enlarged the numbers in minor SOC groups with an increase in precision of the estimates. The associations between occupation and mental health were similar in the 1993-2000 combined dataset to the 2000 dataset and did not alter the conclusions we derived from the 2000 dataset.

\section{Discussion}

Prevalence rates of common mental disorder were assessed by occupational classifications: major SOC group, sub- 
major SOC group, minor SOC group and additional unit groups. The main mental health outcome was reported was the proportion scoring 12 or more on the CIS-R (common mental disorder).

We compared rates of common mental disorder for separate occupations with the mean for the total sample or with a reference group. This reference group was comprised of managers (Managers and Administrators for major SOC groups, specialist managers for minor SOC groups) selected because they were the largest occupational group. Major SOC groups are very broad in occupational classification and include a range of occupations with different characteristics. Thus, a comparison of rates across major SOC groups may not be especially informative about specific occupations. However, the large numbers of participants in major SOC groups means that the rates are likely to be robust. Rates of common mental disorder in sub-major and minor categories may be more informative about specific occupations. The disadvantage of these specific groups is that they contain fewer participants and hence the reliability of rates is less certain. Thus, it is necessary to compare rates of common mental disorder across the levels of occupational classification to interpret these findings.

We initially adjusted for age and sex in logistic regression analyses. We then further adjusted for marital status, family type, housing tenure and financial difficulties to account for non-work factors that might influence common mental disorder and be related to occupation. Adjustment for housing tenure and financial difficulties could be viewed as over-adjustment because they are associated with income from a specific occupation. Further adjustment for long-standing physical illness was important as it is associated with occupation and is a risk factor for common mental disorder in itself. This adjustment might also be seen as over-adjustment because physical illness may be a mediating or moderating factor on the pathway from occupation to common mental disorder.

\section{Occupations with low risk of common mental disorders}

Rates of common mental disorder were low in men in major SOC groups across a range of occupations that seem to have little in common: plant and machine operatives, professionals, craft and related and 'other' occupations. Income varies widely across these groups from high (professionals) to low (plant and machine operators). This does not seem to be a plausible explanation for low rates of common mental disorder. Similarly, skill discretion or opportunity for use of skills may be typical of professionals but it is less likely to be the case for many plant and machine operatives. Thus, skill discretion does not seem to be a sufficient explanation for low rates of
Common Mental Disorder, as concluded in Danish studies [31].

In sub-major groups, low rates were found in other professional occupations, drivers and mobile machine operators, industrial plant and machine operators and assemblers. Blue-collar occupations, in the past, with prolonged manual labour, have been associated with higher rates of physical ill-health. Working conditions for these skilled occupations may have improved recently. Additionally, these occupations can be self contained and may not have high levels of psychological demands that are a risk factor for common mental disorder. Business and finance professionals have low rates; the European Working Conditions Survey (EWCS) suggests that people in this sector have favourable physical working conditions, high levels of skill discretion and good social support-although this may have changed with recent economic depression [9].

Occupations with high risk of common mental disorders

High rates of disorder were found in sales occupations, especially for women, in associate professional and technical occupations, in clerical/secretarial occupations, personal and protective services and managers and administrators. In minor SOC groups, general managers in government and large organisations may have high levels of accountability and a lack of long-term job security and may not always receive adequate work support. They may also be under pressure to achieve targets, and, this may add up to considerable job demands [30] Managers in transport and storage may be exposed to similar targets making high psychological work demands. Buyers/mobile sales persons may be under pressure to get sales in a very competitive market-again this may represent psychological demands and work overload. High psychological demands may be important contributors to the higher risk of common mental disorder in these occupations. There are notable sex difference in rates of Common Mental Disorder within buyers, brokers and salespersons. Could working conditions and work ethos be too focused on men in these occupations at the expense of women? Certainly other studies have found that employees who are in a male minority in female-dominated occupations such as teaching, healthcare and social work are at greater risk of affective disorders, although selection may play a role here too [32].

It is not clear why Scientific technicians and professional technical occupations NES had higher risks of disorder. In Clerks, higher rates of common mental disorder may relate to their relatively low status amongst whitecollar occupations and exposure to repetitive and monotonous work. 
Specific additional SOC unit groups

There are a group of occupations that have high rates of common mental disorder in several studies. These include primary and secondary teachers, welfare community youth workers, security staff, waiters, bar staff, nurse auxiliaries and care assistants. These occupations both involve working face to face with the general public, including school pupils, clients, patients or customers but also usually involve a degree of responsibility coupled with some unpredictability in how their clients might behave towards them. This 'emotional labour' may be hazardous to mental health. The high expectations from the public, risk of violence and verbal aggression $[9,28,33]$, is often associated with an expectation that the professional will mask their own emotional needs to their cost in terms of mental health [11, 31, 34]. Administrative and performance expectations despite low financial rewards add to effort-reward imbalance of these occupations [25, 29]. Low control from the job strain model and effort-reward imbalance have been shown to have independent effects on depressive symptoms [7]. The lack of significant associations in these occupations in logistic regression analyses may be because of too few participants in some of these groups although bar staff continue to be at high risk. Bar staff are also exposed to easy access to alcohol, a known risk factor for common mental disorder [15, 34]. The EWCS also suggests that in general hotel and restaurant staff are exposed to poor ergonomic conditions, unfavourable hours, high job strain, often unskilled work and discrimination [9].

It is a useful exercise to compare occupations across industries. Similar jobs have different rates of common mental disorder by industrial sector. Thus, people in the same occupation may be more or less at risk depending on the context in which they work. These contextual differences may relate plausibly to working conditions and the status of the occupation within the different types of organisation or industry. Even across the same occupation, there may be differing levels of support, skill discretion and demands in different industries.

The ONS psychiatric morbidity study and other North American and European studies

The results of this survey are similar to the UK SWI95 survey [12]. In the SWI95 survey, the prevalence of workrelated stress, depression and anxiety was highest in nurses and teachers, with the second highest prevalence amongst care workers, managers and professionals. By contrast, construction and processing occupations had a low prevalence of these disorders [12]. Teachers, healthcare and social workers and female general managers also had higher rates of depression and anxiety in the Danish workforce, whilst male corporate managers, scientists, mechanics and finance personnel had lower rates [31]. Sales persons also had higher rates of depression in the Norwegian Hordaland Health Study [22].

Two North American psychiatric interview studies suggest high rates of major depressive disorder amongst certain groups that were also at risk in the ONS Psychiatric Morbidity Study. These include sales, administrative, clerical, secretarial, kitchen workers and teachers [8, 21]. In a Canadian study, high rates were found in labourers, machine operators, kitchen staff and cleaners [17]. Highrisk groups in a European study using the General Health Questionnaire included typists, nurses, waiters, managers, supply clerks and social workers [4]. At the same time, there were discrepancies: machine operators/assemblers had low rates of common mental disorder in the UK but high rates of depression in North America [10, 21]. There may be considerable diversity of working conditions within these occupations that may contribute to these differing rates.

Given that there are occupational differences in the prevalence of common mental disorder a number of factors may explain the observed differences. First, occupations vary in terms of the hazards in the physical environment encountered by employees. Second, since most employees have some degree of choice as to which occupation they pursue, self-selection may play a role in observed occupational differences. Third, occupations vary in terms of the psychosocial conditions experienced by employees, like low control, high work demands, role conflict, and co-worker support. Role conflict and effort-reward imbalance have been identified by Wieclaw as important in jobs like teaching and social work where people are committed to the work but their status is often undervalued [31]. Fourth, occupations may differ in other factors like income obtained from the occupation, socio-economic status (SES) and education that have an impact on depression but are not directly part of the psychosocial work environment. The importance of psychosocial work characteristics may also vary by SES: job insecurity has been found to more salient in low SES workers and demands and support in high SES workers [23]. Fifth, there may be exposure to working conditions harmful to mental health that are specific to certain occupations.

\section{Conclusion}

In conclusion, there are occupational differences in common mental disorders and the reasons for these differences are complex. Once the causes are better understood then effective interventions can be put in place to improve the psychosocial and physical conditions at work. Further research is needed to combine psychosocial job characteristics with occupational data to help to understand how 
much job characteristics may explain occupational differences in mental health.

Acknowledgments We thank the staff of the Office for National Statistics who were involved in the fieldwork and data preparation of the Psychiatric Morbidity Among Adults Living in Private Households 2000 survey. The data collection was funded by the Department of Health and the Scottish Executive Health Department. However, the views expressed in this paper are those of the authors alone and not necessarily those of the Department of Health or Scottish Executive. This paper and the analyses it describes were funded by the Health and Safety Executive (HSE). Its contents, including any opinions and/or conclusions expressed are those of the authors alone and do not necessarily reflect HSE policy.

Open Access This article is distributed under the terms of the Creative Commons Attribution Noncommercial License which permits any noncommercial use, distribution, and reproduction in any medium, provided the original author(s) and source are credited.

\section{References}

1. Bender A, Farvolden P (2008) Depression and the workplace: a progress report. Curr Psychiatry Rep 10:73-79

2. Bonde JP (2008) Psychosocial factors at work and risk of depression: a systematic review of the epidemiological evidence. Occup Environ Med 65:438-445

3. Bourbonnais R, Brisson C, Moisan J, Vezina M (1996) Job strain and psychological distress in white-collar workers. Scand J Work Environ Health 22:139-145

4. Bultmann U, Kant I, Van Amelsvoort LGPM, Van Den Brandt PA, Kasl SV (2001) Differences in fatigue and psychological distress across occupations: results from The Maastricht Cohort Study of fatigue at work. J Occup Environ Med 43:976-983

5. Buxton JW, Singleton N, Melzer D (2005) The mental health of early retirees-national interview survey in Britain. Soc Psychiatry Psychiatr Epidemiol 40:99-105

6. de Lange AH, Taris TW, Kompier MA, Houtman IL, Bongers PM (2003) "The very best of the millennium": longitudinal research and the demand-control-(support) model. J Occup Health Psychol 8:282-305

7. Dragano N, He Y, Moebus S, Jöckel K-H, Erbel R, Siegrist J, for the Heinz Nixdorf Recall Study (2008) Two models of job stress and depressive symptoms. Soc Psychiatry Psychiatr Epidemiol 43:72-78

8. Eaton WW, Anthony JC, Mandel W, Garrison R (1990) Occupations and the prevalence of major depressive disorder. J Occup Med 32:1079-1087

9. European Foundation for the improvement of living and working conditions (2009) A sector perspective on working conditions. http://www.eurofound.europa.eu/publications/htmlfiles/ef0814.htm, accessed November 2009

10. Grosch JW, Murphy LR (1998) Occupational differences in depression and Global Health: Results from a National Sample of US workers. J Occup Environ Med 40:153-164

11. Hochschild AR (1983) The managed heart: commercialization of human feeling. University of California Press, Berkeley

12. Jones JR, Hodgson JT, Clegg TA, Elliott RC (1998) Self-reported work-related illness in 1995: results of a Household Survey. HSE Books, Sudbury

13. Kasl SV (1998) Measuring job stressors and studying the health impact of the work environment: an epidemiologic commentary. J Occup Health Psychol 3:390-401
14. Kawakami N, Haratani T (1999) Epidemiology of job stress and health in Japan: review of current evidence and future directions. Ind Health 37:174-186

15. Kessler RC, Crum RM, Warner LA, Shulenberg J, Anthony JC (1997) Lifetime co-occurrence of DSM-III-R alcohol abuse and dependence with other psychiatric disorders in the National Comorbidity Survey. Arch Gen Psychiatry 54:313-321

16. Lewis G, Pelosi AJ, Araya R et al (1992) Measuring psychiatric disorder in the community: a standardized assessment for use by lay interviewers. Psychol Med 22:465-486

17. Marchand A (2007) Mental health in Canada: are there any risky occupations and industries? Int J Law Psychiatry 30:272-283

18. McCaig R (1998) Occupational health approaching the millennium: applying Legge's experience. In: McCaig R, Harrington M (eds) The changing nature of occupational health. HSE Books, Sudbury

19. Muntaner C, Pulver AE, McGrath J, Eaton WW (1993) Work environment and schizophrenia: an extension of the arousal hypothesis to occupational self-selection. Soc Psychiatry Psychiatr Epidemiol 28:231-238

20. OPCS Standard Occupational Classification, vol 3 (1991) HMSO, London

21. Roberts RE, Lee ES (1993) Occupation and the prevalence of major depression, alcohol, and drug abuse in the United States. Environ Res 61:266-278

22. Sanne B, Mykletun A, Dahl AA, Moen BE, Tell GS (2003) Occupational differences in levels of anxiety and depression: the Hordaland Health Study. J Occup Environ Med 45:628-638

23. Simmons LA, Swanberg JE (2009) Psychosocial work environment and depressive symptoms among US workers: comparing working poor and working non-poor. Soc Psychiatry Psychiatr Epidemiol 44:628-635

24. Singleton N, Bumpstead R, O'Brien M, Lee A, Meltzer H (2001) Psychiatric morbidity among adults living in private households 2000. National Statistics, London

25. Stansfeld SA, Fuhrer R, Shipley MJ et al (1999) Work characteristics predict psychiatric disorder: prospective results from the Whitehall II Study. Occup Environ Med 56:302-307

26. Stansfeld SA, Head J, Rasul F, Singleton N, Lee A (2003) Occupation and mental health: secondary analyses of the ONS Psychiatric Morbidity Survey of Great Britain. HSE Books, Sudbury

27. Stansfeld S, Bridget Candy B (2006) Psychosocial Work Environment and mental health: a meta-analytic review. Scand J Work Environ Health 32:443-462

28. Tennant C (2001) Work-related stress and depressive disorders. J Psychosom Res 51:697-704

29. Van Vegchel N, de Jonge J, Bosma H et al (2005) Reviewing the effort-reward imbalance model: drawing up the balance of 45 empirical studies. Soc Sci Med 60:1117-1131

30. Wall TD, Bolden RI, Borrill CS, Carter AJ, Golya DA, Hardy GE, Haynes CE, Rick JE, Shapiro DA, West MA (1997) Minor psychiatric disorder in NHS trust staff: occupational and gender differences. Br J Psychiatry 171:519-523

31. Wieclaw J, Agerbo E, Mortensen PB, Bonde JP (2005) Occupational risk of affective and stress-related disorders in the Danish workforce. Scand J Work Environ Health 31:343-351

32. Wieclaw J, Agerbo E, Mortensen PB, Bonde JP (2006) Risk of affective and stress-related disorders in human service professions. Occup Environ Med 63:314-319

33. Wieclaw J, Agerbo E, Mortensen PB, Burr H, Tüchsen F, Bonde JP (2006) Work related violence and threats and the risk of depression and stress disorders. J Epidemiol Community Health 60:771-775

34. Wilhelm K, Kovess V, Rios-Seidel C, Finch A (2004) Work and mental health. Soc Psychiatry Psychiatr Epidemiol 39:866-867 